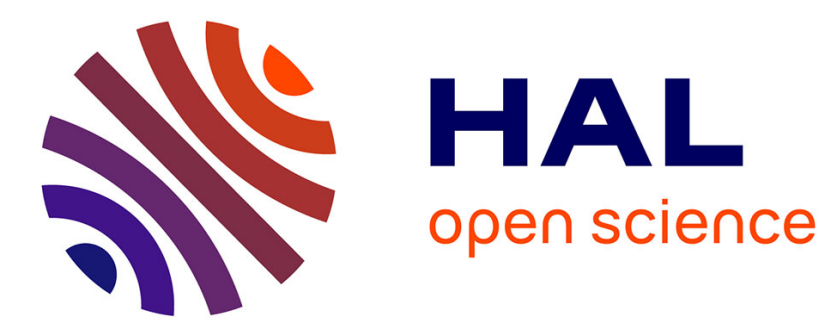

\title{
Assessment of HWD ability to detect debonding of pavement layer interfaces
}

\author{
Amir Sadoun, Mickael Broutin, Jean Michel Simonin
}

\section{To cite this version:}

Amir Sadoun, Mickael Broutin, Jean Michel Simonin. Assessment of HWD ability to detect debonding of pavement layer interfaces. MCD2016, 8th International conference on Mechanisms of Cracking and Debonding in Pavements, Jun 2016, NANTES, France. 6p, 10.1007/978-94-024-0867-6_106 . hal01364066

\section{HAL Id: hal-01364066 https://hal.science/hal-01364066}

Submitted on 12 Sep 2016

HAL is a multi-disciplinary open access archive for the deposit and dissemination of scientific research documents, whether they are published or not. The documents may come from teaching and research institutions in France or abroad, or from public or private research centers.
L'archive ouverte pluridisciplinaire HAL, est destinée au dépôt et à la diffusion de documents scientifiques de niveau recherche, publiés ou non, émanant des établissements d'enseignement et de recherche français ou étrangers, des laboratoires publics ou privés. 


\title{
Assessment of HWD ability to detect debonding of pavement layer interfaces
}

\author{
SADOUN Amir ${ }^{1}$, BROUTIN Michaël ${ }^{1}$, SIMONIN Jean-Michel ${ }^{2}$ \\ ${ }^{1}$ French civil Aviation technical center, 31 av. du Maréchal Leclerc; 94381 Bonneuil France, \\ michael.broutin@aviation-civile.gouv.fr \\ ${ }^{2}$ French institute of science and technology for transport development and network, \\ IFSTTAR, Route de Bouaye, CS4, F-44344 Bouguenais France, jean- \\ michel.simonin@ifsttar.fr
}

\begin{abstract}
Usual Falling or Heavy Weight Deflectometer (F/HWD) backcalculation methods assume that pavement layers are fully bonded. In order to assess the ability of HWD testing to detect debonding of the interfaces between pavement layers, the French civil Aviation technical center (STAC) performed an HWD campaign on the circular Accelerated Pavement Testing (APT) facility of IFSTTAR in Nantes, on an experimental pavement with artificially created local sliding interface between bituminous surface and base layers,. Both the sound and the defective tested pavement sections present a common structure in terms of subgrade, materials and layer thicknesses. HWD tests have been performed along a large circular arc covering the two sections. A fine spatial measure discretization $(10 \mathrm{~cm})$ was used. The experimentation shows that the HWD is a valuable tool for the detection of extended interface defects detection, the central deflection being significantly affected by the interface quality, the outer deflections being less sensitive to this parameter. This paper presents raw deflection results, allowing to precisely locate the underlying defects in the test section. Then a numerical study is detailed, which aims at assessing the effect of the bonding conditions over deflections. The theoretical analysis of this HWD survey is performed in two steps: firstly, on the basis of the finite elements method (FEM) dynamical modeling of the HWD test developed by the STAC, a backcalculation of material moduli is performed using the deflections measured in the sound area. Secondly the backcalculated moduli are introduced in a forward calculation, taking into account the debonded interface. The numerical results are compared with experimental deflections measured over the defects. They are consistent with in-situ results.
\end{abstract}

Keywords Debonded interface, APT, HWD testing, Dynamical backcalculation. 


\section{Experimentation presentation}

A full-scale experimentation was launched on the IFSTTAR's APT facility [Kerzrého, 2014] in 2012 to assess the ability of non destructive testing (NDT) devices to detect interface defects. It included debonded areas artificially created in the pavement during the construction works. The STAC performed HWD tests on both the sound pavement and the areas presenting localized interface defects.

The pavement structure is presented in [Simonin et al., 2012]. It is composed of a $6 \mathrm{~cm}$ thick wearing course of Bituminous Concrete (BC) and a $8 \mathrm{~cm}$ thick base layer of Road Base Asphalt material (RBA) over a $30 \mathrm{~cm}$ thick unbound granular material (UGM). These material properties meet the specifications of the NF EN 13108 series of standards. The depth to bedrock (corresponding to the APT concrete structure) is $3 \mathrm{~m}$. The modulus of the subgrade between UGM and concrete was estimated using static plate tests. A $70 \mathrm{MPa}$ value was obtained, corresponding to a value in the 140-210 MPa range for dynamic tests. Three $2 \mathrm{~m} \times 1.5 \mathrm{~m}$ rectangular defects, $2 \mathrm{~m}$ apart from each other, were created at the interface between the bituminous layers by means of a thin layer of sand, a geotextile or the absence of tack coat.

HWD tests were performed with a $10 \mathrm{~cm}$ step, starting from $0.90 \mathrm{~m}$ before the first defect boundary, to $0.90 \mathrm{~m}$ after the end of the third one. Tests were performed in March 2012, when the pavement had not yet been circulated by the APT device, so that the areas without defects can be considered as sound. Mean temperature in the bituminous layer during the HWD was in the $15-20^{\circ} \mathrm{C}$ range.

\section{Qualitative approach}

Figure 1 presents raw results relative to peak deflection values recorded on the central geophone (positioned at plate center) as a function of the distance between the loading plate and the defects boundary $\mathrm{D}_{\mathrm{X}}$. HWD peak load was kept constant for the whole survey (equal to $82 \mathrm{kN} \pm 2 \mathrm{kN}$ ).

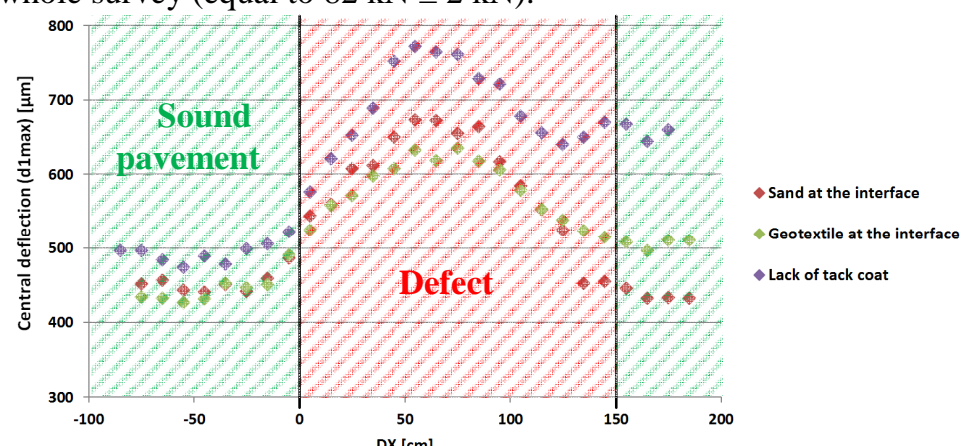

Fig. 1 Central deflection peak values - in-situ measurements 
It appears that the central deflection increases significantly (on average plus $53 \%$ ) when moving from sound pavement to defect area. This underlines that HWD testing is relevant for the detection of such size of localized defects. Same analysis on outer geophone ( $2.40 \mathrm{~m}$ offset from load center) shows that measured peak deflection is almost constant $(\sim 30 \pm 1 \mu \mathrm{m})$ regardless of $\mathrm{D}_{\mathrm{X}}$. This was predictable considering that the defect is relative to the upper layers. It is thus confirmed that outer deflections are almost exclusively influenced by deep layers deformations, whereas the center deflection is impacted by the whole structure.

\section{$3 \quad$ Numerical analysis}

The analysis methodology proposed in this paper is as follows: a dynamical 3D-backcalculation on the "sound" pavement is first performed, in order to determine the layer material moduli. Then several forward calculation using the aforebackcalculated moduli are performed, which correspond to each experimental load plate position. These forward calculations include the defect in the modeling. This paragraph describes first the modeling used for back and forward calculations. The backcalculation results are then displayed. The synthesis of the forward calculations is finally presented, and compared to in-situ data.

\subsection{Modeling}

The modeling is inspired by the 2D- axisymmetric dynamical method developed by the STAC for sound flexible pavement analysis [Broutin, 2010] or [STAC, 2014]. The FE calculation, performed using the CESAR-LCPC software [LCPC, 2005], has been adapted for the 3D-case under study. The $3 \mathrm{~m}$ deep bedrock is taken into account in the modeling. The defect was modeled using doublenodes. For each pair of nodes, linear relationships enable fixing at zero the vertical relative displacements of the two nodes, whereas relative horizontal displacements remain free. Therefore the two conditions of complete debonding and noninterpenetration between layers are verified.

Using symmetry considerations, half a plate and half a defect are taken into account in the model. Figure 2 a) presents the mesh used for the "sound" pavement configuration, i.e. with a load plate outside the defect area (in practice at $0.90 \mathrm{~m}$ left from boundary). Figure $2 \mathrm{~b}$ ) displays in a schematic view the different meshes used for forward calculations. These meshes are similar to the previous one, but moving the defect along the $\mathrm{X}$-axis. Let again $\mathrm{D}_{\mathrm{X}}$ be the distance between load plate center and defect boundary. In both cases the research version of the PREDIWARE software [Broutin, 2010] developed by the STAC for flexible pavement HWD dynamical back-and forward calculation automation was adapted. 

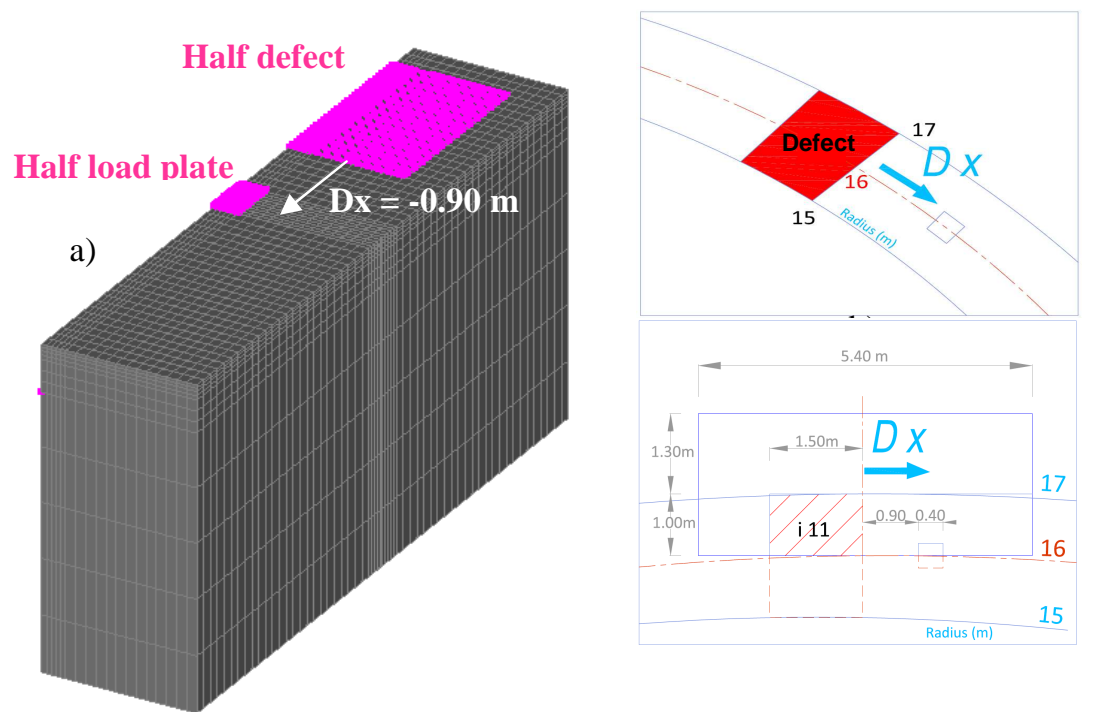

Fig. 2 Back- and forward calculation a) FE mesh used for backcalculation, $D_{\mathrm{X}}=-0.90 \mathrm{~m}$; b) defect positions, $D_{X}=-0.90$ to $D_{X}=2.40 \mathrm{~m}$, positioned between the $15 \mathrm{~m}$ and $17 \mathrm{~m}$ APT radius.

\subsection{Backcalculation}

Figure 3 presents the backcalculation results, obtained with PREDIWARE. In-situ measurements are displayed in solid lines whereas numerical deflection signals appear in dotted lines. For readability purposes only five deflections are displayed, corresponding to geophones $1,3,7,10$ and 12 , respectively positioned at $0,0.4$, $0.9,1.5$ and $2.1 \mathrm{~m}$ from load center.

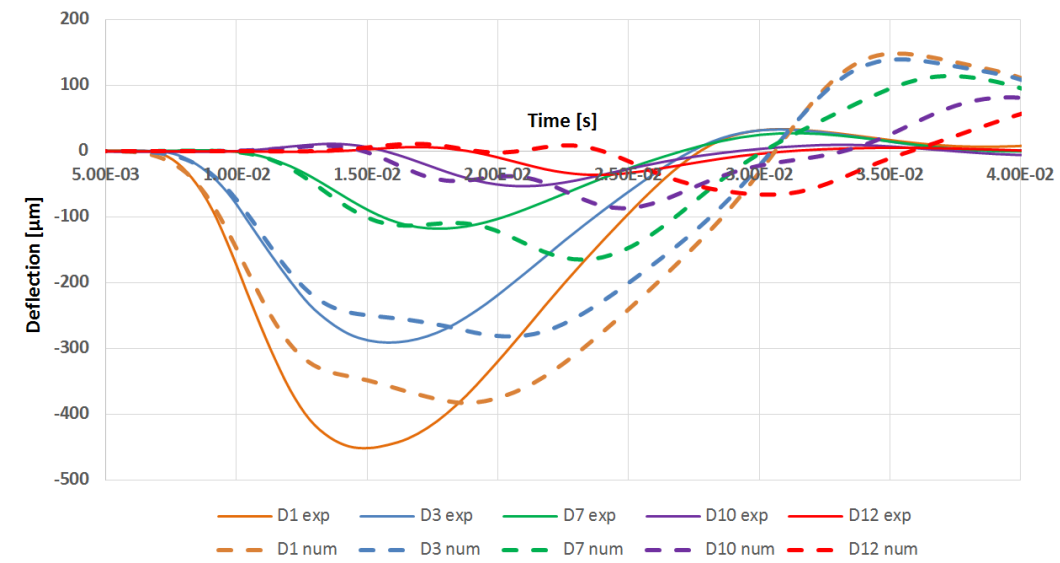

Fig. 3 Backcalculation results - Distance between load plate and defect $D_{X}=0.90 \mathrm{~m}$ 
Note that no structural damping has been considered in the current calculation. This may explain that numerical curves present slight slope changes between 15 and $20 \mathrm{~ms}$ which are not encountered for the smoother curves from in-situ results.

Backcalculated moduli corresponding to Figure 3 fitting are given in Table 1, and compared with typical values at temperature between 15 and $20^{\circ} \mathrm{C}$ and a frequency of $30 \mathrm{~Hz}$, representative of the HWD impulse loading.

Table 1 Backcalculated moduli

\begin{tabular}{lcccc}
\hline & BC & RBA & UGM & Subgrade \\
\hline Backcalculated moduli $[\mathrm{MPa}]$ & 7000 & 7000 & 240 & 180 \\
\hline Expected values $[\mathrm{MPa}]$ & $4500-6500$ & $8000-11000$ & $210-315$ & $140-210$ \\
\hline
\end{tabular}

Subgrade and UGM moduli are consistent with expectations. Moduli of bituminous material fall between the expected ranges, with the $\mathrm{BC}$ value slightly higher and the RBA value slightly lower than expected; this is in accordance with general observations made in [Broutin, 2010] showing that bituminous materials moduli are generally misestimated due to the fact that their viscoelastic behavior is neglected. Work is in progress in STAC to better account for this effect.

\subsection{Forward calculation results}

Figure 4 depicts (blue points) central deflection peak values extracted from forward calculations results for $\mathrm{D}_{\mathrm{X}}=-0.90$ to $2.40 \mathrm{~m}$, using the backcalculated moduli in Table 1.

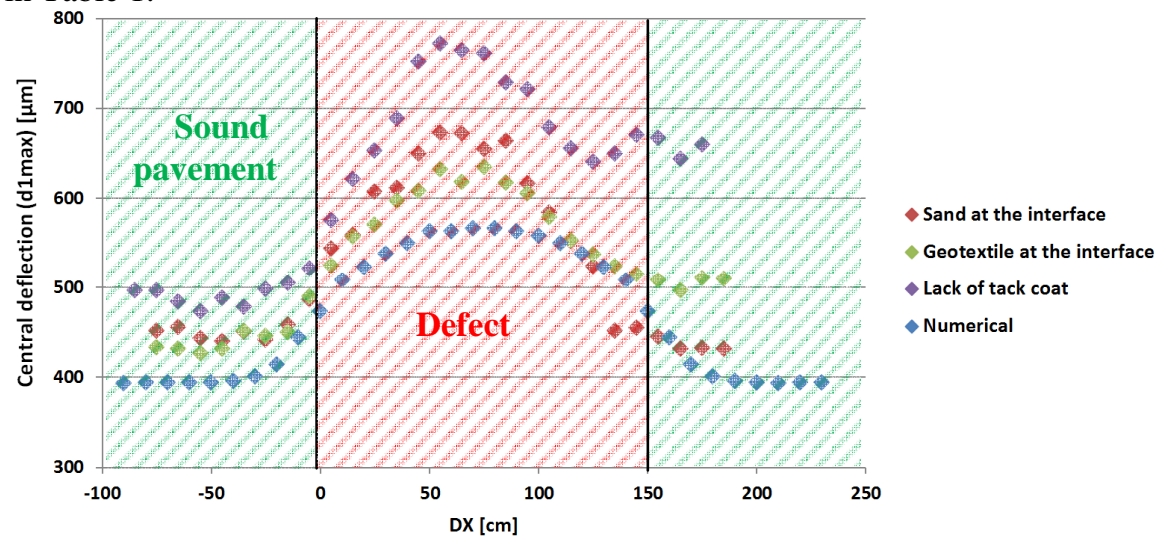

Fig. 4 Central deflection peak values - comparison between numerical results and in-situ measurements 
It shows that numerical resolution enables bringing to light the defect. The deflection evolution shape and order of magnitude are consistent with in-situ results. Difference observed may be explained by the fact that the backcalculation fitting is not perfect. Actually numerical peak value of the central deflection (geophone d1) under study in this paper is slightly lower than the experimental one according to Figure 3. This explains partly the underestimation of the deflections on this geophone in the forward calculations performed from backcalculated moduli. Furthermore defects have been considered as independent in the calculation, even if they are relatively close to each other $(2 \mathrm{~m})$.

\section{$4 \quad$ Conclusion and future work}

It has been shown in this paper that HWD is a valuable tool for detecting largesize $(1.50 \mathrm{~m} \times 2 \mathrm{~m}$ in this study) defects. Qualitative analysis using raw central and outer deflections enables identifying a surface defect. Visual inspection or complementary tests should enable differentiating between interface defect and bulk problems (material damage leading to a fall in modulus). The possibility of integrating localized interface defects in the modeling has also been proven for both back-and forward calculations. These results will be completed in the future using on the one hand complementary calculations taking into account bituminous materials viscoelastic behavior, and on the other hand the analysis of additional insitu data. To achieve this, 2012 test survey presented in this paper was reiterated in 2013 at pavement mid-life. STAC plans a last HWD test survey in 2016, after completion of the full scale APT life cycle test.

\section{References}

Broutin M. (2010) Assessment of flexible airfield pavements using Heavy Weight Deflectometers; Development of a FEM dynamical time-domain analysis for the backcalculation of structural properties, $\mathrm{PhD}$ thesis, http://www.stac.aviation-civile.gouv.fr/chaussee/ausc_hwd.php Accessed 10 oct 2014

Kerzreho J.-P. (2014) Setup and use of the IFSTTAR's fatigue test track, RGRA ERR review 23-24, Fall 2013- Spring 2014.

LCPC (2005) Numéro spécial CESAR-LCPC, Bulletin des Laboratoires des Ponts et Chaussées, $\mathrm{N}^{\circ}$ 256-257

STAC (2014) Guidance for flexible pavement testing using Heavy Weight Deflectometer (HWD)

Simonin J.-M., Fauchard C., Hornych P., Guilbert V., Kerzrého J-P., Trichet S., Detecting unbounded interface with non destructive techniques. 7th Rilem International Conference on Cracking in Pavements, June 20-22 2012, Delft, The Netherlands. RILEM Bookseries, 4: 179190, DOI: 10.1007/978-94-007-4566-7_18, ISBN 978-94-007-4565-0, 